\title{
The Use of Multi-instrumental Approach to Teaching Physics
}

\author{
Radek Nemec ${ }^{1}$, Filip Sramek ${ }^{1}$ and Andrea Berkova ${ }^{1}$ \\ ${ }^{1}$ University of Hradec Kralove, Faculty of Education, Czech Republic
}

\begin{abstract}
This article describes the results of research focused on the impact of the use of multi-instrumental approach to teaching physics. This multi-instrumental approach to teaching physics is utilized by tools of CAA (Computer-aided assessment) and SMPSL (Systems for measurement using a computer). The effect of connecting the CAA and SMPSL as variable was examined through a pedagogical experiment to confirm the positive effect of using this multi-instrumental approach on the quality of elementary school pupils' knowledge of physics.
\end{abstract}

\section{Introduction}

Multi-instrumental approach means connecting different instruments. In this case, system CAA (Computer-aided assessment) [1] and (SMPSL) systems for measurement using a computer [2] were interconnected. The aim of this research is to find out whether using the interconnected multi-instrumental approach influences the quality of elementary school pupils' knowledge of physics.

Pre-test and post-test will be used for data collection. Before teaching with the help of multi-instrumental approach, a pre-test will be given to pupils. Post-test will be conducted after lessons where multi-instrumental approach was used. The test will be distributed among parallel groups. Multi-instrumental approach will not be applied to the control group (teaching will be in the traditional way without help of CAA and SMPSL systems). Multi-instrumental approach will be used in the experimental group. The results will be compared and conclusions will be drawn from them concerning the effect of multi-instrumental approach on pupils' knowledge of physics.

\section{Used Instruments}

CAA (Computer-aided assessment) platforms are suitable for testing and practicing mathematical knowledge. An example of such system is the platform Maple T. A. (Testing and Assessment), which was established by integrating computational capabilities of computer algebra system Maple to CAA system. CAA platforms can help consolidate student understanding, support selfdirected learning and make it easier for instructors to manage growing class sizes [3]. Mathematical platforms CAA also contain special features useful for testing mathematical knowledge such as working with graphs, series and mathematical symbols. In addition to practicing mathematical knowledge it is also available to use CAA platforms in physics.

SMPSL (Systems for measurement using a computer) is system that enables the collection, management and processing of data obtained by the measuring device that is connected to the computer. Such experiments are also called computer-aided experiments. The SMPSL (Measurement System Using a Computer in School Lab) enables using sensors connected to the hardware of the system to a PC evaluation program. The evaluation is created using a graphical representation of values from the computer.

\subsection{Methodology of Research}

As already mentioned, for examining differences in pupils' knowledge an objectively scored didactic tests were created, which were used as pre and post-tests. For the creation of didactic test the CAA system Maple TA was used. Maple T.A (Web-based Testing and Assessment for Math Courses) is an educational system distributed by Maplesoft to support training mathematics and science subjects [4]. Maple T.A provides students rich interactive environment using CAS (Computer Algebra System) Maple. Questions of various types were included in the tests.

To maintain objectivity, mainly closed questions (e.g. multiple choice) and exceptionally open questions with brief answers were selected.

\section{Pre-test}

Before the execution of research, a pre-test was conducted to determine comparable knowledge of control and experimental groups.

The results are summarized in the following tables.

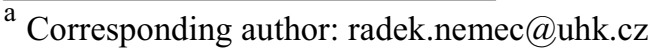


Table 1 shows the test results of the control and experimental group. Point range was from 0 to 10 points.

Table 1. Points of Pre-test

\begin{tabular}{|c|c|c|}
\hline $\begin{array}{c}\text { Number of } \\
\text { pupil }\end{array}$ & $\begin{array}{c}\text { Control } \\
\text { gr. }\end{array}$ & Exp. gr. \\
\hline 1 & 10 & 10 \\
\hline 2 & 10 & 9 \\
\hline 3 & 9 & 9 \\
\hline 4 & 9 & 9 \\
\hline 5 & 8 & 9 \\
\hline 6 & 8 & 8 \\
\hline 7 & 8 & 8 \\
\hline 8 & 7 & 8 \\
\hline 9 & 7 & 8 \\
\hline 10 & 6 & 7 \\
\hline 11 & 6 & 6 \\
\hline 12 & 6 & 6 \\
\hline 13 & 5 & 5 \\
\hline 14 & 5 & 5 \\
\hline 15 & 4 & 5 \\
\hline 16 & 4 & 5 \\
\hline 17 & 4 & 4 \\
\hline 18 & 4 & 4 \\
\hline 19 & 3 & 3 \\
\hline 20 & 3 & 3 \\
\hline 21 & 1 & 2 \\
\hline 22 & 0 & 2 \\
\hline 23 & & 1 \\
\hline 24 & & 0 \\
\hline
\end{tabular}

Table 2. F-test of Pre-test

\begin{tabular}{|l|l|l|}
\hline & $\begin{array}{l}\text { Contr. } \\
\text { gr. }\end{array}$ & Exp. $g r$. \\
\hline Expected value & 5,773 & 5,667 \\
\hline Variance & 7,613 & 8,232 \\
\hline
\end{tabular}

\begin{tabular}{|l|l|l|}
\hline Observation & 22 & 24 \\
\hline Difference & 21 & 23 \\
\hline $\mathrm{F}$ & 0,925 \\
\hline $\mathrm{P}(\mathrm{F}<=\mathrm{f})(1)$ & 0,431 \\
\hline $\mathrm{F}$ krit (1) & 0,485 \\
\hline
\end{tabular}

Hypothesis of identical variances was not rejected because the test criterion $\mathrm{F}$ was smaller than $\mathrm{F}$ crit. It was further applied to the two-sided T-test to determine whether pupils from both the control and experimental groups have comparable knowledge before the experiment. The reader can get acquainted with the results in Table 3.

Table 3. T-test of Pre-test

\begin{tabular}{|l|l|l|}
\hline & $\begin{array}{l}\text { Contr. } \\
\text { gr. }\end{array}$ & Exp. gr. \\
\hline Expected value & 5,773 & 5,667 \\
\hline Variance & 7,613 & 8,232 \\
\hline Observation & 22 & 24 \\
\hline Common variance & 7,936 \\
\hline Hyp. Median difference value & 0,000 \\
\hline Difference & 44,000 \\
\hline t Stat & 0,128 \\
\hline P(T<=t) (1) & 0,450 \\
\hline t krit (1) & 1,680 \\
\hline P(T<=t) (2) & 0,899 \\
\hline t krit (2) & 2,015 \\
\hline
\end{tabular}

The test criterion $t$ is less than $t$ crit and therefore the hypothesis of identical means is not rejected. It is assumed that pupils from both the control and experimental groups have comparable knowledge before teaching itself.

In the following table the basic statistics can be seen (Table 4).

Table 4. Descriptive statistics of Pre-test

\begin{tabular}{|l|l|}
\hline Control group & \\
\hline & \\
\hline Expected value & 5,773 \\
\hline
\end{tabular}


CSCC 2016

\begin{tabular}{|c|c|}
\hline Standard error of the mean & 0,588 \\
\hline Median & 6 \\
\hline Modus & 4 \\
\hline Standard deviation & 2,759 \\
\hline Variance & 7,613 \\
\hline Kurtosis & $-0,503$ \\
\hline Skewness & $-0,279$ \\
\hline Minimum & 0 \\
\hline Maximum & 10 \\
\hline Suma & 127 \\
\hline Total & 22 \\
\hline Significance level $(95,0 \%)$ & 1,223 \\
\hline Experimental group & \\
\hline Expected value & 5,667 \\
\hline Standard error of the mean & 0,586 \\
\hline Median & 5,5 \\
\hline Modus & 9 \\
\hline Standard deviation & 2,869 \\
\hline Variance & 8,232 \\
\hline Kurtosis & $-0,975$ \\
\hline Skewness & $-0,297$ \\
\hline Minimum & 0 \\
\hline Maximum & 10 \\
\hline Suma & 136 \\
\hline Total & 24 \\
\hline Significance level $(95,0 \%)$ & 1,212 \\
\hline
\end{tabular}

For clarity, the reader can see the histogram. Table 5, 6, Figure 1, 2.

Table 5. Histogram of Pre-test

\begin{tabular}{|l|l|l|}
\hline Control gr. & & \\
\hline Points & Frequency & Cumul. \% \\
\hline 2 & 2 & $9,09 \%$ \\
\hline
\end{tabular}

\begin{tabular}{|l|l|l|}
\hline 4 & 6 & $36,36 \%$ \\
\hline 6 & 5 & $59,09 \%$ \\
\hline 8 & 5 & $81,82 \%$ \\
\hline 10 & 4 & $100,00 \%$ \\
\hline
\end{tabular}

Table 6. Histogram of Pretest

\begin{tabular}{|l|l|l|}
\hline Exp. Gr. & & \\
\hline Points & Frequency & Cumul. \% \\
\hline 2 & 4 & $16,67 \%$ \\
\hline 4 & 4 & $33,33 \%$ \\
\hline 6 & 6 & $58,33 \%$ \\
\hline 8 & 5 & $79,17 \%$ \\
\hline 10 & 5 & $100,00 \%$ \\
\hline
\end{tabular}

\section{Histogram Control gr.}

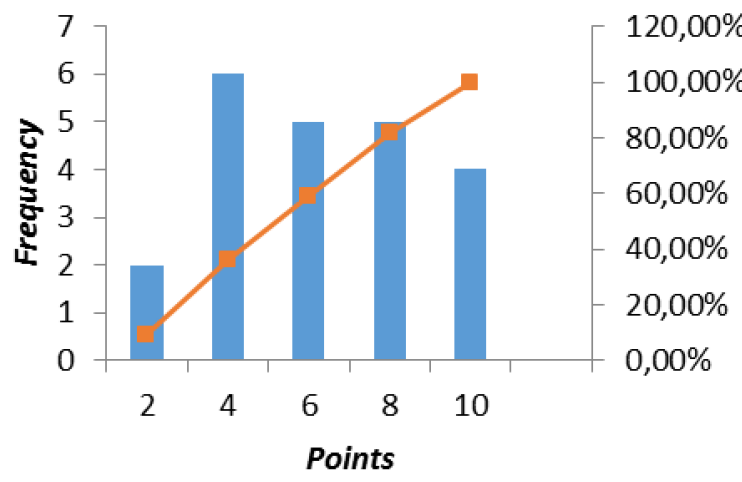

Frequency $\longrightarrow$-Cumul. \%

Fig. 1. Histogram of Pretest Control gr. 


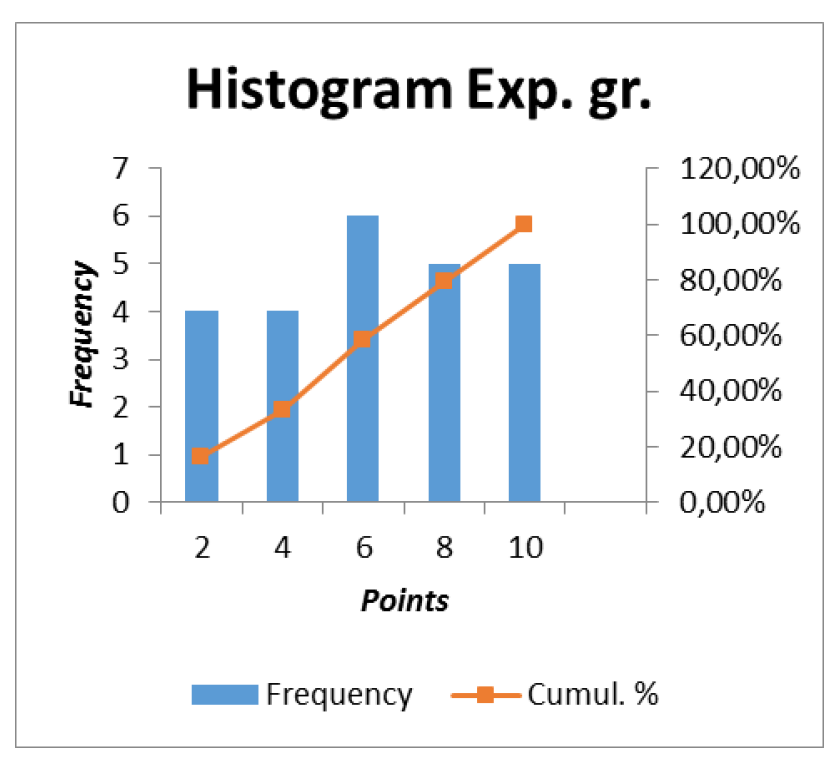

Fig. 2. Histogram of Pre-test Experimental gr.

\section{Post-test}

The experiments use of research focused on the impact of CAA and the use of measurement systems using computers in school science laboratories to acquire more knowledge than when teaching without CAA and measurement system using a computer are as follows. The results are summarized in the following tables.

Therefore an experiment was subsequently conducted - teaching control and experimental groups ended with post-test (pre-test identical).

Table 7 shows the test results of the control and experimental group. Point range was from 0 to 10 points.

Table 7. Points of Post-test

\begin{tabular}{|l|l|l|}
\hline \multicolumn{1}{|c|}{ Number of pupil } & $\begin{array}{c}\text { Control } \\
\text { gr. }\end{array}$ & Exp. gr. \\
\hline 1 & 10 & 10 \\
\hline 2 & 9 & 10 \\
\hline 3 & 9 & 9 \\
\hline 4 & 8 & 9 \\
\hline 5 & 7 & 9 \\
\hline 6 & 7 & 9 \\
\hline 7 & 7 & 8 \\
\hline 8 & 6 & 8 \\
\hline 9 & 6 & 8 \\
\hline 10 & 6 & 8 \\
\hline 11 & 6 & 7 \\
\hline 12 & 5 & 7 \\
\hline 13 & 5 & 7 \\
\hline 14 & 5 & 7 \\
\hline
\end{tabular}

\begin{tabular}{|l|l|l|}
\hline 15 & 4 & 6 \\
\hline 16 & 3 & 6 \\
\hline 17 & 3 & 5 \\
\hline 18 & 3 & 5 \\
\hline 19 & 2 & 4 \\
\hline 20 & 1 & 4 \\
\hline 21 & & 2 \\
\hline
\end{tabular}

Table 8. F-test of Post-test

\begin{tabular}{|l|l|l|}
\hline & Contr. gr. & Exp. gr. \\
\hline Expected value & 5,600 & 7,048 \\
\hline Variance & 5,937 & 4,548 \\
\hline Observation & 20,000 & 21,000 \\
\hline Difference & 19,000 & 20,000 \\
\hline F & 1,305 \\
\hline P(F $<=$ f) $(1)$ & 0,279 \\
\hline F krit (1) & 2,137 \\
\hline
\end{tabular}

The hypothesis of identical variance whereas the $\mathrm{F}$ test criterion is smaller than $\mathrm{F}$ crit is not rejected (Table 8). Therefore, T-test can be used again (Table 9).

Table 9. T-test of Post-test

\begin{tabular}{|l|l|l|}
\hline & Control gr. & \multicolumn{1}{|c|}{ Exp. gr. } \\
\hline Expected value & 5,600 & 7,048 \\
\hline Variance & 5,937 & 4,548 \\
\hline Observation & 20,000 & 21,000 \\
\hline Common variance & 5,224 \\
\hline $\begin{array}{l}\text { Hyp. Median } \\
\text { difference value }\end{array}$ & 0,000 \\
\hline Difference & 39,000 \\
\hline $\mathrm{t}$ Stat & $-2,027$ \\
\hline $\mathrm{P}(\mathrm{T}<=\mathrm{t})(1)$ & 0,025 \\
\hline $\mathrm{t}$ krit $(1)$ & 1,685 \\
\hline $\mathrm{P}(\mathrm{T}<=\mathrm{t})(2)$ & 0,050 \\
\hline $\mathrm{t}$ krit $(2)$ & 2,023 \\
\hline
\end{tabular}

Based on these results it is suggested that students in the experimental group showed acquisition of more knowledge than when teaching without measurement system using a computer. This can be seen in the box plot (Fig. 3). 


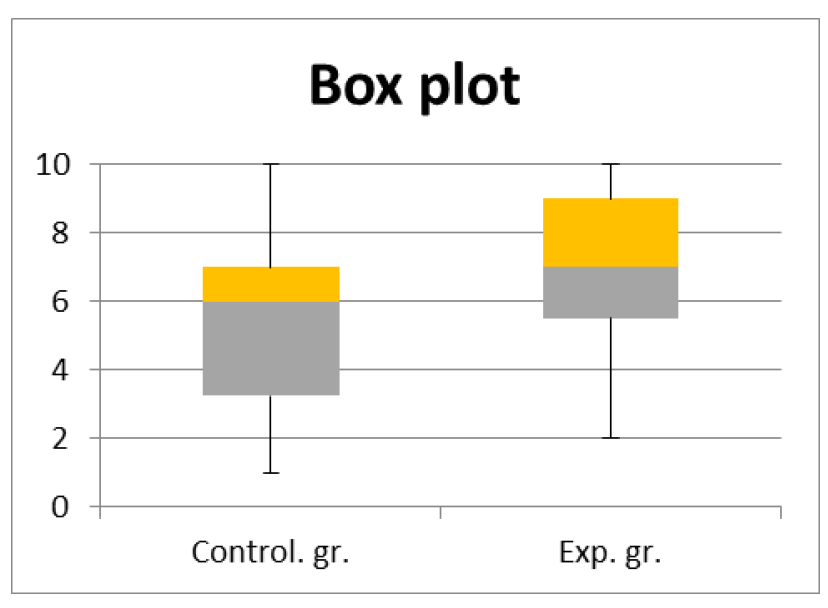

Fig. 3. Boxplot of Posttest.

In the following table the basic statistics can be seen (Table 10).

Table 10. Descriptive statistics of Post-test

\begin{tabular}{|l|l|}
\hline Control group & \\
\hline & \\
\hline Expected value & 5,600 \\
\hline Standard error of the mean & 0,545 \\
\hline Median & 6 \\
\hline Modus & 6 \\
\hline Standard deviation & 2,437 \\
\hline Variance & 5,937 \\
\hline Kurtosis & $-0,574$ \\
\hline Skewness & $-0,062$ \\
\hline & 1,140 \\
\hline Minimum & 1 \\
\hline Maximum & 10 \\
\hline Suma & 20 \\
\hline Total & 7,048 \\
\hline Significance level (95,0\%) & 7,465 \\
\hline & \\
\hline Experimental group & \\
\hline & \\
\hline Expected value & \\
\hline Standard error of the mean & \\
\hline & 1,12 \\
\hline
\end{tabular}

\begin{tabular}{|l|l|}
\hline Median & 9 \\
\hline Modus & 2,133 \\
\hline Standard deviation & 4,548 \\
\hline Variance & $-0,006$ \\
\hline Kurtosis & $-0,684$ \\
\hline Skewness & \\
\hline & 2 \\
\hline Minimum & 10 \\
\hline Maximum & 148 \\
\hline Suma & 21 \\
\hline Total & 0,971 \\
\hline Significance level $(95,0 \%)$ & \\
\hline & \\
\hline
\end{tabular}

For clarity, the reader can see the histogram. Table 11, 12, Figure 4, 5.

Table 11. Histogram of Post-test

\begin{tabular}{|l|l|l|}
\hline Control gr. & & \\
\hline Points & Frequency & Cumul. $\%$ \\
\hline 2 & 2 & $10,00 \%$ \\
\hline 4 & 4 & $30,00 \%$ \\
\hline 6 & 7 & $65,00 \%$ \\
\hline 8 & 4 & $85,00 \%$ \\
\hline 10 & 3 & $100,00 \%$ \\
\hline
\end{tabular}

Table 12. Histogram of Post-test

\begin{tabular}{|l|l|l|}
\hline Exp. Gr. & & \\
\hline Points & Frequency & Cumul. \% \\
\hline 2 & 1 & $4,76 \%$ \\
\hline 4 & 2 & $14,29 \%$ \\
\hline 6 & 4 & $33,33 \%$ \\
\hline 8 & 8 & $71,43 \%$ \\
\hline 10 & 6 & $100,00 \%$ \\
\hline
\end{tabular}




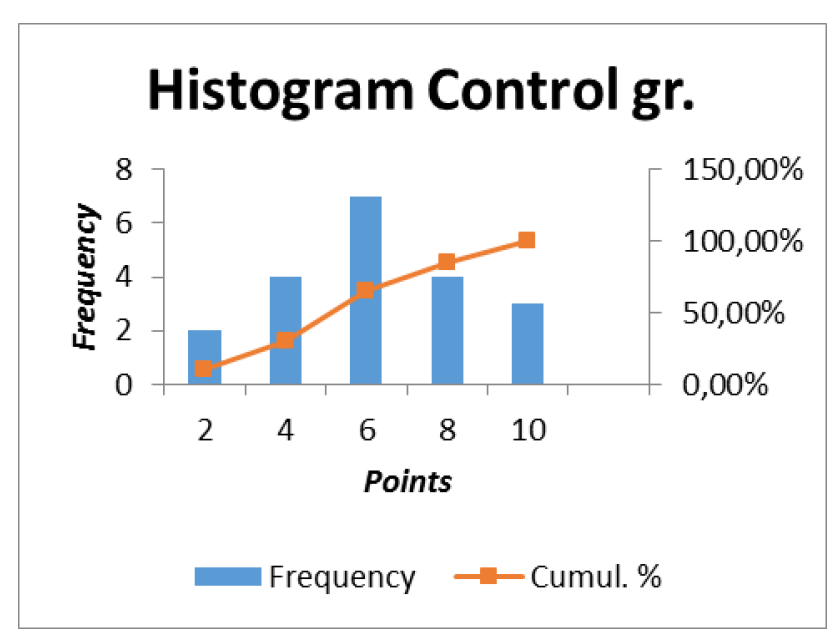

Fig. 4. Histogram of Post-test Control gr.

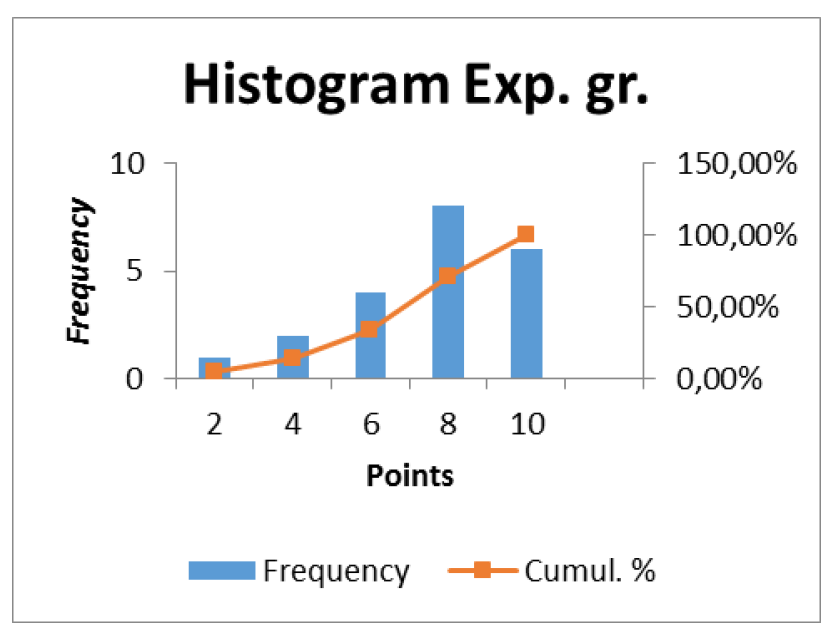

Fig. 5. Histogram of Post-test Experimental gr.

\section{Conclusion}

Use of CAA and system for measurement using a computer, as indicated by the research found a positive effect on the acquisition of knowledge in the Czech secondary schools. The test results of the experimental group, as shown by the Box plot, are considerably higher. The reader can find similar interesting approaches to teaching in papers [4-6]. It would certainly be interesting for future arrangement to evaluate this experiment with regard to students' approaches to learning and studying such as in [7].

\section{ACKNOWLEDGMENT}

This research work has been supported by specific research project of the University of Hradec Kralove, Faculty of Education in 2016 (No. 2142).

\section{References}

1. A. Berkova, (2014) 'Approaches To Learning And Studying In Mathematical Analysis Classes', INTED 2014 Proceedings (8th International Technology, Education and Development Conference), IATED, Valencia, pp. 2978-2982.

2. R. Nemec, J. Triska, J. Sedivy. System SMPSL. In: The 4th NAUN International Conference on CIRCUITS, SYSTEMS, CONTROL, SIGNALS (CSCS '13). Valencia, 2013, ISBN: 978-960-474318-6. P. 43-47.

3. Technical Whitepaper. (2015) 'Challenges and Solutions in Automated STEM Assessment', [Online], Maplesoft, a division of Waterloo Maple Inc. 2015, Available:

http://www.maplesoft.com/contact/webforms/Whitep apers/STEMAssessment.aspx [15 February 2016].

4. Maple T.A. - Web-based Testing and Assessment for Math Courses - Maplesoft. [online]. [cit. 2016-0226]. Available:

http://www.maplesoft.com/products/mapleta.

5. R. Nemec, A Berkova, S. Hubalovsky, The Use of Method of Multidisciplinary Approach, Modeling and Simulation in Learning of Gear Ratios. International Journal of Mathematics and Computers in Simulation, volume 10, 2016 ISSN: 1998-0159

6. R. Nemec, A. Berkova, P. Hanzalova, (2016) 'The Connection of System SMPSL (System for measurement using a computer in the school laboratory) and CAA (Computer Aided Assessment) for Demonstration of Mathematical Modeling of Angle،. WSEAS Transactions on Information Science and Applications. ISSN 1790-0832.

7. A. Berkova, J. Kulicka, (2015) 'Modelling and Simulation in Teaching of Future Teachers of Mathematics', ICERI 2015 Proceedings (8th International Conference of Education, Research and Innovation), IATED, Seville, pp. 7525-7533. 